\title{
A fotografia na pesquisa acadêmica: sobre visibilidades e possibilidades do conhecer
}

\section{Photography in academic research: on visibilities and possibilities to know}

\begin{abstract}
Resumo:
Este estudo discute a fotografia como ferramenta na pesquisa acadêmica que analisa os modos de subjetivação e os efeitos de poder na configuração das possibilidades do ver e dos jogos de produção das visibilidades. Para tanto, enfatiza os tensionamentos entre a fotografia, o fotógrafo e o ato de fotografar, tendo como referência o contexto da pesquisa-intervenção e o que temos convencionado chamar de intervenção fotográfica. Neste contexto, a experiência do fotografar mostra-se como estratégia do conhecer e do refletir sobre as visibilidades moldadas nos cotidianos e seus efeitos na produção de modos de sujeição e de resistências. Estas reflexões têm como objetivo discutir como as metodologias dobram-se e desdobram-se enquanto experiências no conhecer a vida e como estratégias de produção de sujeitos e de modos de subjetivação.

Palavras-chave: Fotografia. Modos de subjetivação. Pesquisa acadêmica.
\end{abstract}

\section{Abstract:}

This study discuss the use of photographs as tools in academic research analyzing the subjectivation ways and the effects of power in the configuration of the possibilities of seeing and in the struggles in the production of visibilities. It emphasizes the tensions between the photograph, the photographer and the photographic act, having as reference research-intervention and what we are calling photographic intervention. In this context, to photograph reveals itself a strategy to known and to think about the visibilities molded in daily life and its effects in the production of resistances and subjectivation ways. These reflections have as objective discuss how the methodology folds and unfolds as experiences of understanding life and as strategies of production of subjects and subjectivation ways.

Keywords: Photograph. Subjetcitivation ways. Academic research.

TITTONI, Jaqueline; OLIVEIRA, Renata Ghisleni de; SILVA, Paula Marques da; TANIKADO, Grace. A Fotografia na Pesquisa Acadêmica: sobre visibilidades e possibilidades de conhecer. Informática na Educação: teoria \& prática, Porto Alegre, v. 13, n. 1, p. 59-66, jan./jun. 2010.

\author{
Jaqueline Tittoni \\ Renata Ghisleni de Oliveira \\ Paula Marques da Silva \\ Grace Tanikado \\ Universidade Federal do Rio Grande do Sul
}

\section{Introdução}

A história da fotografia mescla-se com a história da tecnologia moderna, do desenvolvimento de equipamentos, aparatos tecnológicos e produtos capazes de capturar, fixar e registrar imagens da vida cotidiana. Também inscreve-se no discursividade da ciência moderna e nos seus efeitos de produção de verdades sobre o mundo e sobre a vida, como estratégia para buscar a legitimação e revelação da realidade. Estas relações entre o ver, o registrar e o conhecer serão analisadas neste texto, pensando as possibilidades da fotografia na pesquisa acadêmica, como uma ferramenta de trabalho, equipamento, técnica de produção e fixação de imagens e modos de ver. A discussão sobre a relação intensa entre a fotografia e a verdade mostra a inscrição da fotografia no contexto da modernidade como um recurso técnico capaz de evidenciar a realidade e como forma de comprovação de sua existência. A ciência e seus atributos de objetividade e comprobabilidade encontraram na fotografia uma importante aliada, mas, ao 
permitir o acesso e o registro das imagens, também evidenciou outras visibilidades possíveis. Pode-se imaginar, como sugere Foucault (1988) em O Nascimento da Clínica, a surpresa que uma visibilidade microscópica trouxe no século XVI, possibilitando a observação de seres novos e desvelando outras visibilidades.

Assim, ao mesmo tempo que mostra evidências de uma situação ou período da história através da sua função de registro de imagens, a fotografia "abre-se" evocando imagens pouco visíveis e provocando o olhar. A fotografia pode convocar o olhar a olhar para si próprio, buscando os fatores que podem estar presentes nos jogos de visibilidade-invisibilidade, ampliando e problematizando os modos de ver e as verdades que podem sustentá-los. A tensão entre fotografia e verdade esteve desde sempre presente, como sugere Sontag (2004, p. 102), relatando que uma década depois do desenvolvimento do processo fotográfico negativo-positivo de Talbot, já existia a primeira técnica para retocar os negativos e, na Exposição Universal de Paris de 1855, um fotógrafo alemão apresentou duas versões de uma mesma fotografia, uma retocada e outra não. Segundo a autora, "a notícia de que a câmara podia mentir tornou muito mais popular o ato de fotografar" (SONTAG, 2004, p. 102). Este fotógrafo alemão é Franz Hanfstaengl, a quem é atribuída a invenção da técnica do retoque do negativo. A produção de artifícios técnicos capazes da manipulação de imagens, tensiona, assim, o realismo fotográfico, sendo que, para Fontcubierta (2004, p. 15) " toda a fotografia é uma ficção que se apresenta como verdadeira".

Estes tensionamentos entre fotografia e verdade e a inscrição da fotografia nos regimes de verdades presentes na sua produção serão analisados neste texto desde o lugar de pesquisadores acadêmicos, onde a fotografia coloca-se como possibilidade de problematização do próprio conhecimento científico. Ao tratarmos da utilização da fotografia neste campo, analisaremos a fotografia e o ato de fotografar como uma estratégia metodológica inscrita nos jogos de verdade que produzem e legitimam discursos sobre a ciência. Para tanto, a fotografia é enfocada no seu caráter múltiplo, como ficção e como registro, como irredutível às lógicas dualísticas e antagônicas, expressando, ao mesmo tempo, modos de ver já legitimados historicamente e aber- turas que indicam outras passagens, outros fluxos e produções. Ao tensionar a ciência e suas verdades com a possibilidade da invenção e da arte e, ao mesmo tempo, problematizar a arte, ao mostrar-se como registro, documento e referente, a fotografia mostra seu caráter de irredutibilidade e sua potencialidade na produção acadêmica. Para tanto, faremos algumas breves considerações sobre as tensões entre fotografia e verdade e apresentaremos uma proposta de estratégia de pesquisa acadêmica que se utiliza da fotografia como principal ferramenta. Ao longo do texto serão apresentadas algumas fotografias de pequenos registros cotidianos, feitos pelas autoras, realizados como exercício de sensibilização e exploração de pequenos visíveisinvisíveis cotidianos.

\section{Sobre a fotografia, verdades e visibilidades}

$O$ ato de ver, como bem lembra Berger (2000) define um lugar no mundo, um ponto de vista marcado por convenções e modos de ver que podem definir e orientar o olhar na produção do que pode e deve ser visto. As visibilidades possíveis, para além do ver, são registradas ao longo da história, de modo a marcar algumas frações de espaço-tempo neste campo de diversidade. Estas visibilidades podem ser fixadas através de artifícios que buscam uma certa suspensão do tempo, evocando um desejo de duração. Este desejo de marcar já está presentes na pintura ou no desenho e também na fotografia, indicando o que Berger chama de uma evidência de que "uma imagem pode ultrapassar em duração aquilo que ela representava" (BERGER, 2000, p. 12). Imagem, representação e duração são temas recorrentes na discussão sobre a fotografia e se atualizam quando se propõe pensar a fotografia na pesquisa científica. Neste caso, a imagem pode ser pensada como forma de evidenciar os fatos e situações, a representação como forma de acesso e comprovação da realidade e a duração como forma de marcar, neste território de verdades científicas, a fugacidade da vivência e das visibilidades cotidianas.

Berger e Mohr (2007), considerando que a câmara fotográfica foi inventada em 1839, afir- 
mam que o positivismo, a câmara e a sociologia cresceram juntas, sustentadas pela crença de que "a precisão substituiria as matemáticas, o planejamento resolveria os conflitos sociais, a verdade ocuparia o lugar da subjetividade e o que fora obscuro e estivesse oculto na alma seria iluminado pelo conhecimento empírico" (BERGER; MOHR, 2007, p. 99). Para Batchen (2004) até mesmo o mais conservador historiador da fotografia estaria de acordo com a idéia de que a invenção e a difusão do meio fotográfico estão vinculados a " chegada da modernidade e aos seus processos econômicos, sociais e culturais no princípio do século XIX" (BATCHEN, 2004, p. 185). A câmera fotográfica estaria, assim, produzida na discursividade da técnica, da verdade e do desenvolvimento, como equipamento e aparato produzido para evidenciar a realidade e comprovar - ou legitimar - verdades sobre a vida.

No entanto, como uma tecnologia dos modos de ver, a fotografia poderá suportar outras relações entre experiência e sentido e entre tempo e espaço, que poderão indicar outras produções que extrapolam a lógica da ciência e da verdade. Para além da busca de uma origem fotográfica e fundamentado na genealogia foucaultiana, Batchen (2004, p. 41) propõe pensar no aparecimento de "uma prática discursiva 'regular', cujo objeto de desejo parece ser a fotografia". Nesta perspectiva é o desejo de fotografar que se coloca em questão, ressaltando que a fotografia como discurso vem, também, tensionar a lógica científica experimental, os modelos de progresso e de evolução evidentes no período de seu surgimento.

Para Barthes (1984), a fotografia está além dos moldes da racionalidade e objetividade instauradas pela ciência e considera inviável enquadrar a fotografia em um corpus teórico estruturado, definindo-a como inclassificável. Para o autor, não há nada que defina a escolha do que pode ou deve ser fotografado e tudo pode se tornar imagem e, assim, a fotografia é atravessada pelo acaso, pela prática da escolha, pelos movimentos da subjetividade. O autor enfatiza que a fotografia é sempre contingencial, uma fatalidade. Não há fotografia sem alguém ou alguma coisa, a fotografia sempre traz consigo seu referente, não podendo nunca se distinguir dele; é sempre invisível, pois ao nos depararmos com ela, é com o seu referente que entramos em con- tato. Importante ressaltar que a contribuição de Barthes é evidenciada na discussão sobre o surgimento e o estatuto de complexidade da fotografia, ainda que sua posição com relação a o referente fotográfico seja muito discutida a partir, sobretudo, da perspectiva das diferentes estratégias de montagem e remontagens das fotografias. Ainda que com importante contribuição, a noção de referente e de sua indissociabilidade da imagem fotográfica mostram-se como marcas da idéia de fotografia como revelação e reprodução de uma provável realidade, fortemente discutida na história da produção fotográfica. A noção de contingencialidade da fotografia fica, assim, ressaltada na discussão proposta pelo autor.

Para Batchen, a melhor forma de definir o surgimento da fotografia seria como um "acontecimento, que se inscreve no espaço deixado pela derrota da filosofia natural e da visão de mundo característica da ilustração" (BATCHEN, 2004, p. 41). Como acontecimento, a fotografia inscreve-se na discussão sobre os limites do pensamento moderno através do tensionamento das dualidades natureza-cultura, espaço-tempo, sujeito-objeto, sujeitorepresentação, cotinuidade-descontinudiade e diferença-semelhança, na medida em que esta prática resiste às lógicas de dualidade e oposição. A fotografia é, ao mesmo tempo, imagem, modos de ver, recursos técnicos trazidos pelos equipamentos e pelo conhecimento de quem o manipula, possibilidades do olhar e mais uma multiplicidade de fatores que tornam impossível reduzi-la a condições de registro ou de criação. É na sua multiplicidade que se coloca sua potência e a fotografia pode ser pensada como "o jogo de uma diferença que sempre difere de si mesma" (BATCHEN, 2004, p. 187). Como esta tentadora irresolução, como definiu Batchen (2004), a fotografia aparece como efeito da sociedade da técnica e do desenvolvimento, mas, também, irredutível a ela, gerando outras aberturas para produções de conhecimento.

Fontcubierta (1998) discute fotografia e verdade, tensionando as imagens de modo a provocar a noção de verdade, recorrendo à fotomontagem. Para o autor, a fotografia pode sustentar, subverter ou inscreve-se na lógica da produção de verdades - tal qual a ciência - principalmente se baseada na idéia da fotografia como registro do verdadeiro, da realidade. 


\section{A fotografia na pesquisa acadêmica: algumas reflexões}

Estas discussões terão como ponto de partida uma série de fotografias feitas pelos autores, como exercícios de sensibilização e de produção do campo de produção dos diferentes estudos, com o objetivo de sensibilizar para os pequenos detalhes que compõe o cotidiano e expressam idéias complexas e permeadas de moralidade, que, ainda que sejam marcas nos territórios que habitamos, mostram-se pouco visíveis aos olhares menos sensibilizados. As imagens a seguir mostram estas visibilidades cotidianas, indicando que o exercício do olhar faz parte do ato de pesquisar, convocando o olhar do pesquisador sobre o seu próprio trabalho. A partir das fotografias, segue nossas reflexões sobre a fotografia e a pesquisa acadêmica.

A fotografia tem sido utilizada como ferramenta metodológica na pesquisa em perspec-

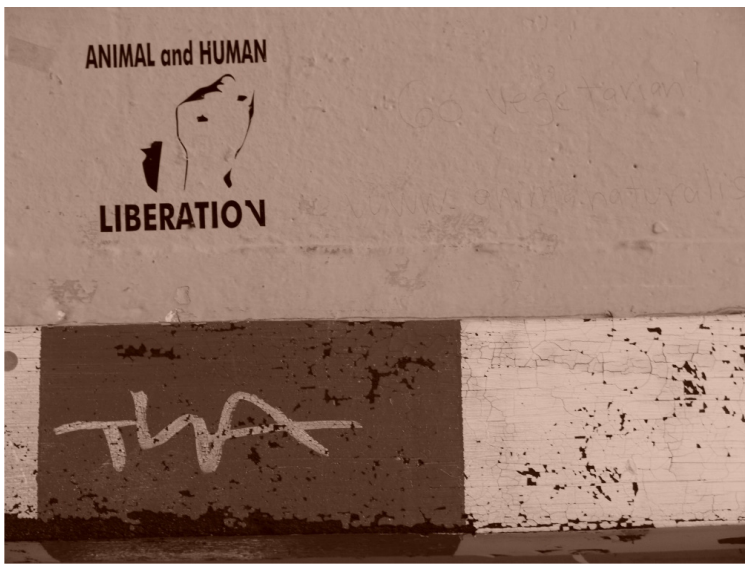

Jaqueline Tittoni

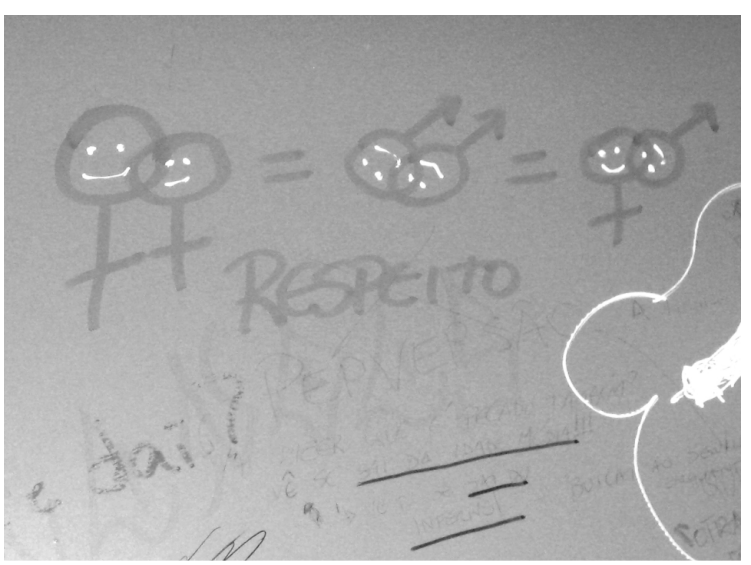

Paula Marques da Silva tivas diversas como na Psicologia Social (MAURENTE, 2005; TITTONI, 2004; DIEHL, 2007; AMADOR; FONSECA; KIRST, 2008), na Psicologia do Desenvolvimento (NEIVA-SILVA, 2003), na Sociologia (VON SIMSON, 2006), na pesquisa documental (VASCONCELLOS, 1995) e na Antropologia Visual (ACHUTTI, 2004; TACCA, 1993) não se configurando como um suporte estanque, definitivo e com regras imutáveis. Ao contrário, existe uma grande diversidade de usos da fotografia que indicam sobre diferentes formas de produzir conhecimento.

Em nossa experiência, em especial, o uso da fotografia coloca-se no jogo das visibilida-

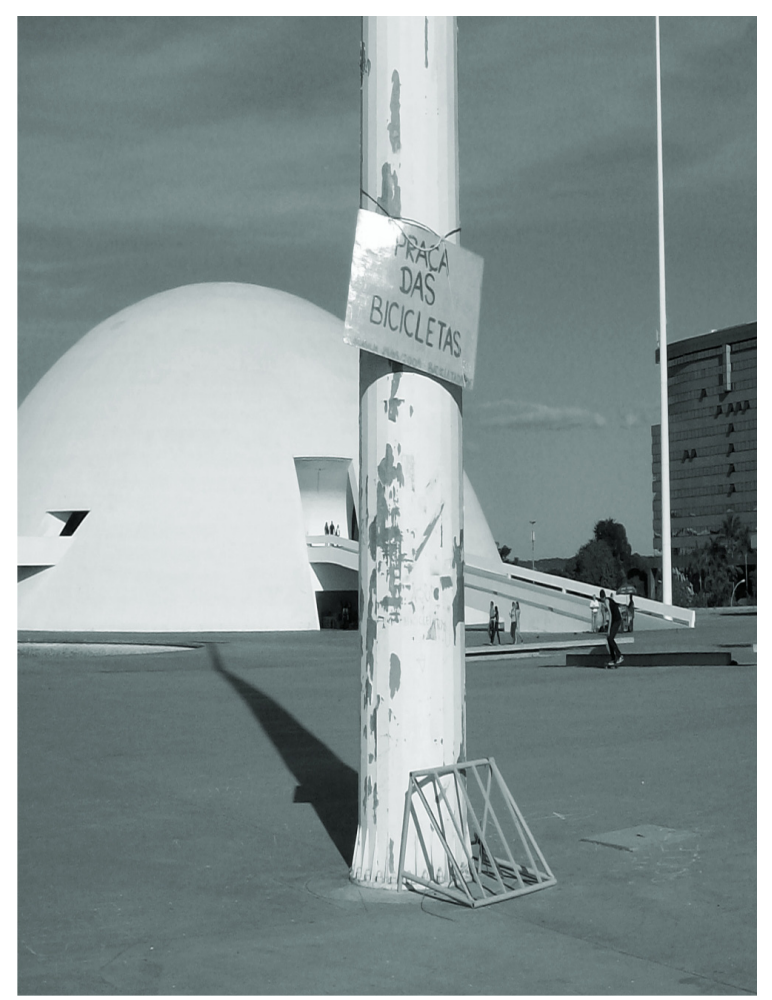

Grace Tanikado

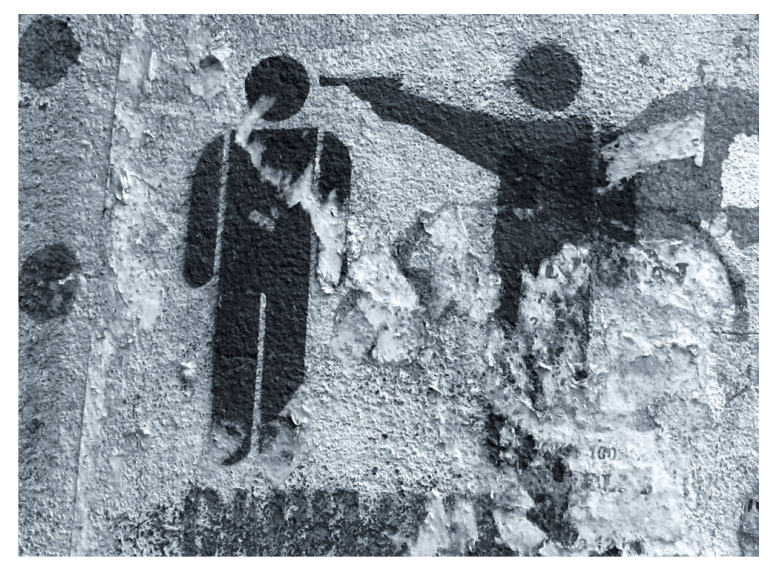

Paula Marques da Silva 
des e invisibilidades proposto na análise dos modos de subjetivação e de poder no pensamento foucaultiano. Como efeito de poder, somos pressionados a algumas visibilidades e construímos algumas possibilidades do ver e, também, a algumas invisibilidades e impossibilidades do ver. Desta forma, nossa proposta de trabalho implica em pensar a fotografia como um processo, onde o ato de fotografar, as possibilidades e impossibilidades do ver, o fotógrafo e a fotografia compõem um jogo onde jogam as diferentes possibilidades em razão da situação, em acordo ou desacordo com ela.

O Fotografar, portanto, amplia-se da produção de imagem, incluindo o impacto do olhar e as visibilidades possíveis. A fotografia, assim, pode traduzir-se em uma arquitetura tensionada pelos sentidos produzidos na experiência de quem fotografa e no olhar que reverbera a imagem, produzindo-se na tensão entre $o$ ato de fotografar, o fotografado e a fotografia.

Flusser (2002), ao discutir o agenciamento fotógrafo e aparelho, convoca a pensar sobre a condição de sujeição do fotografo no ato de fotografar. $O$ autor argumenta que a relação do fotógrafo com a máquina pode se encerrar na condição de mero funcionário do programa, uma vez que este sujeito opera a máquina apenas como fornecedor de input. Este automatismo no operar a máquina e fazer fotografias, pode ser ressignificado na medida em que o fotógrafo passa a jogar contra o próprio aparelho. Esse processo de subversão do aparelho ocorre quando o sujeito rompe com a lógica passiva de apertar um botão e passa a conhecer e desvendar a máquina. Ocorre, também, quando o fotógrafo dá relevância aos sentidos atribuídos ao ato de fotografar, colocando-se na posição de enunciador na produção da imagem.

Barthes (1984) aponta que seu olhar sobre a fotografia não é proveniente da posição de operador, de fotógrafo, e sim de espectador. É a partir dos lugares o sujeito que olha e o sujeito que é olhado que o autor define as três práticas da fotografia: fazer, suportar e olhar. Nesse sentido, o fotografo é o que enquadra, limita, coloca em perspectiva o que quer surpreender através do disparo da máquina. $O$ espectador somos todos nós, ávidos por fotografias de origens diversas, surpreendidos ou imbuídos de indiferença, suportando ou não, os impactos que nos fere a imagem.
Para o autor, a fotografia é constituída de elementos intitulados de studium e punctum. A ligação entre estes elementos é sem regras, trata-se de uma co-presença. O studium refere-se a indicativos que revelam elementos de historicidade, gestos, cenários, ações, conotações culturais da fotografia. No entanto, nem todas as fotografias são dotadas de algo que provoca um abalo, que punge, que se lança como uma marca, uma ferida ao espectador. Esta inquietação ligada a um detaIhe da fotografia é denominada de punctum, onde a fotografia não é mais qualquer, é um suplemento, é o que o espectador acrescenta à imagem, mas que de qualquer forma que já pertence a ela.

$O$ ato de fotografar, assim, implica o lugar de fotógrafo, de espectador e as circunstâncias onde se produzem as fotografias e as visibilidades possíveis. Assim, pode-se pensar que $o$ ato de fotografar se dá na experiência, tomada aqui no sentido atribuído por Foucault (2006), como campo de lutas em que se articulam determinados campos do saber, tipos de normalidade e formas de subjetivação.

$\mathrm{O}$ ato de fotografar implica em escolhas e recortes, dando relevância ao ponto de vista de quem fotografa e a imagem, nesse sentido, deixa de ser somente ilustração de descrições, mas possibilidade de construção a partir de outra forma de escritura. O uso da fotografia como linguagem é o resultado de um ato intencional, marcado pela autoria e pelas possibilidades de visibilidade trazidas pelas éticas do ver. Para Achutti (2004), o fotógrafo é o portador de uma forma específica de escrita, que possibilita uma maneira diferente de interpretar o mundo.

De acordo com Sontag (2004), a sociedade capitalista é estruturada para produzir e consumir imagens e esta lógica está intensamente implicada na maneira como são determinadas nossas necessidades em relação à realidade. A ordem predominantemente mercadológica torna a imagem indispensável para a sobrevivência da economia e estabilidade do corpo social, tornando-se uma norma para como as coisas se mostram para a humanidade e estilizando formas de ver. A fotografia coloca-se, assim, instituindo interpretações da realidade, acomodando a visão e tornando banal o que é inquietante. Assim, a autora afirma que estamos sujeitos à ética do ver, que é um novo código visual, no qual apreendemos o mundo 
através da imagem e que produz ressonâncias na definição do que vale a pena ser olhado e o que pode ser observado. Cria, dessa forma, o belo e o feio, determinando o valor do aparente.

Ao falarmos em uma ética do ver estamos nos referindo a um ponto de vista produzido - um olhar treinado ou pressionado pelos modos de ver legitimados. Esse olhar é atravessado por imagens pautadas nas verdades produzidas, configurando certa arquitetura de códigos, regras e sentidos. Esses códigos vão indicando o que pode e o que não pode ser visto como em uma gramática em que são inscritos olhares do sujeito.

Na perspectiva proposta neste trabalho, a fotografia se diferencia de um suporte passível de uma interpretação de conteúdos, pois não enfatiza a busca de signos projetados na imagem pelo produtor ou mesmo pelo espectador da fotografia, bem como não pressupõe a revelação de verdades subscritas às imagem. Da mesma forma, não há a busca por uma essência de realidade, mas de produções de realidade. A proposta é de estudar as condições de possibilidade de produções de realidade através de produções fotográficas (MAURENTE; TITTONI, 2007). Assim, é possível afirmar que uma fotografia pode ser considerada uma prova de existência, mas nem por isso, considerada uma prova de sentido (DUBOIS, 1990 apud MAURENTE; TITTONI, 2007).

Para Maurente e Tittoni (2007) a utilização da fotografia como estratégia metodológica possibilita a produção conjunta de saberes, não delegando ao sujeito pesquisado somente a função de fornecedor de dados, mas de protagonista do processo de construção de conhecimentos. A fotografia é tomada como parte de um trabalho, um momento de um processo de intervenção em um coletivo.

A proposta de intervenção fotográfica consiste em entregar aos sujeitos uma câmera fotográfica e pedir que eles produzam imagens a partir de um tema ou questão emergente do acompanhamento do grupo, e posteriormente, construam uma narrativa conjunta utilizando as fotografias produzidas. Esta ação é precedida pela realização de oficinas de sensibilização para o olhar fotográfico, apresentando produções e propondo a experimentação desse olhar. A oficina de sensibilização tem como principal objetivo desnaturalizar a idéia de uma fotografia vista apenas como produto, independente dos sentidos inscritos pelo fotógrafo, assim como estimular a sensibilização do olhar para diferentes visibilidades. A idéia é suscitar no grupo a posição de autoria no fotografar, ao mesmo tempo, que estimular o olhar nos jogos das visibilidades possíveis. Essa discussão ocorre através do contato com vários tipos de fotografias como produções de fotógrafos conhecidos - escolhidas de forma aleatória - fotografias dos próprios participantes, fotografias que se configuram como documento, registro, propaganda, assim como fotografias que retratam as várias dimensões do enquadre fotográfico e, por fim, fotografias feitas de materiais diversos compondo uma espécie mosaico, em que a idéia do referente se desacomoda.

Nesse sentido, durante o contato com as várias formas da fotografia inscrever-se no cotidiano, são discutidos a intencionalidade de quem fotografa, o impacto de quem olha a imagem e os diferentes modos de olhar um fotografia. O ato de fotografar vai criando outros contornos, com o desacomodar do olhar treinado e submerso em mundo de imagensproduto, para o de fotografar com inscrição autoral. Tal etapa é necessária, pois o uso dessa linguagem requer um domínio básico de sua operacionalização (ACHUTTI, 2004).

A narrativa produzida é uma construção coletiva, privilegiada para analisar as possibilidades de enunciações e visibilidades que atravessam aquele coletivo. Os recortes escolhidos para a captura fotográfica carregam marcas singulares, que expostos a um coletivo para uma construção conjunta estão passíveis a olhares diferenciados, provocações que já não mais pertencem somente àquele que produziu a imagem. Este mesmo processo ocorre com a equipe de pesquisa/intervenção, que é afetada e também produz afecções naquela produção, num movimento de implicação (AGUIAR; ROCHA, 2007).

A análise da narrativa e de seu processo de produção é baseada nas proposições sobre poder e verdade de Michel Foucault (2007). O poder é compreendido como multiplicidade de correlações de forças que se desloca e provém de toda parte. Não se apresenta como estrutura ou instituição, mas como estratégia complexa. Não existiria, assim, um centro do poder, do qual ele emana, nem mesmo diferentes potências dos quais os sujeitos são dotados, mas uma materialização através de 
dispositivos que estrategicamente produzem alguma forma de verdade. Esta produção se dá no campo de lutas entre o que deve ser e que lugar deve ocupar o sujeito (subjetivação) e o que possibilita a emergência de algo como objeto de conhecimento (objetivação). Nestes jogos de verdade são definidos o que é passível de visibilidade, bem como o que fica invisível. Pode-se afirmar que constituem a ética do ver (SONTAG, 2004), apontando o que é possível de ser olhado a partir do lugar que se ocupa.

Nesse sentido, a fotografia torna-se um elemento que pode provocar a experimenta- ção de uma posição diferenciada pelo sujeito que faz a fotografia: a posição de enunciador, de produtor de uma realidade. A partir disso, é vital a discussão sobre a veiculação de imagens e identificação de autoria destas produções nas pesquisas que utilizam a fotografia como ferramenta, a fim de não alijar a participação dos sujeitos no processo de construção do conhecimento, e não sobrepujar as enunciações que são realizadas a partir da intervenção. Uma reflexão sobre a ética que permeia a pesquisa e seu compromisso vital com os sujeitos que dela participam em detrimento a ordenamentos puramente normativos.

\section{Referências}

ACHUTTI, Luiz Eduardo Robinson. Fotoetnografia da Biblioteca Jardim. Porto Alegre: Ed. da UFRGS, 2004.

AGUIAR, Katia Faria de; ROCHA, Marisa Lopes da. Micropolítica e o Exercício da Pesquisa-Intervenção: referenciais e dispositivos em análise. Psicologia: ciência e profissão, Brasília, v. 27, n. 4, p. 648-663, dez. 2007.

AMADOR, Fernanda Spanier; FONSECA, Tânia Maria Galli; KIRST, Patrícia Gomes. A Fotografia e a Estética dos Corpos Inacabados. Porto Alegre: [s.n.], [200?]. 9 p. Trabalho não publicado.

BARTHES, Roland. A Câmara Clara. Rio de Janeiro: Nova Fronteira, 1984.

BATCHEN, Geoffrey. Imágenes. In: BATCHEN, Geoffrey. Arder em deseos: la concepcion de la fotografia. Barcelona: Gustavo Gilli, 2004. P. 107-175.

BERGER, John. Modos de Ver. Barcelona: Gustavo Gilli, 2000.

BERGER, John; MOHR, Jean. Outra manera de contar. Barcelona: Gustavo Gilli, 2007.

DIEHL, Rafael. Do Mapa à Fotografia: planografias de um espaço louco. 2007. Dissertação (Mestrado) Programa de Pós-Graduação em Psicologia, Universidade Federal do Rio Grande do Sul, 2007, Porto Alegre, BR-RA.

FLUSSER, Vilém. Filosofia da Caixa Preta: ensaios para uma futura filosofia da fotografia. Rio de Janeiro: Relume Dumará, 2002.

FONTCUBIERTA, Joan. Controvisiones: la fotografia otra. In: FONTCUBIERTA, Joan. Ciência y fricicion: fotografia, naturaleza, artifício. Murcio: Ed. Mestizo, 1998. P. 33-55.

FOUCAULT, Michel. História da Sexualidade: o cuidado de si. 18. ed. Rio de Janeiro: Graal, 2007.

MAURENTE, Vanessa. A Experiência de Si no Trabalho nas Ruas Através da Fotocomposição. 2005. Dissertação (Mestrado) - Programa de Pós-Graduação em Psicologia, Universidade Federal do Rio Grande do Sul, 2005, Porto Alegre, BR-RS.

MAURENTE, Vanessa; TITTONI, Jaqueline. Imagens Como Estratégia Metodológica em Pesquisa: a fotocomposição e outros caminhos possíveis. Psicologia e Sociedade, Porto Alegre, v. 19, n. 3, set./dez. 2007. Disponível em: <http://www.scielo.br/scielo.php?script=sci_arttext\&pid=S0102-71822007000300006> Acesso em: 27 abr. 2008. 
NEIVA-SILVA, Lucas. Expectativas Futuras de Adolescentes em Situação de Rua: um estudo autofotográfico. 2003. Dissertação (Mestrado) - Programa de Pós-Graduação em Psicologia do Desenvolvimento, Universidade Federal do Rio Grande do Sul, 2003, Porto Alegre, BR-RS.

SONTAG, Susan. Sobre Fotografia. São Paulo: Companhia das Letras, 2004.

TACCA, Fernando Cury. Sapateiro: o retrato da casa. Boletim Especial do Centro de Memória da Unicamp, Campinas, v. 10, p. 33-47, 1993.

VAsConcellos, Maria da Penha C. Memórias da Saúde Pública: a fotografia como testemunha. São Paulo: Hucitec-Abrasco, 1995.

VON SIMSON, Olga. Brancos e Negros no Carnaval Popular Paulistano. In: SAMAIN, Etienne. O Fotográfico. São Paulo: SENAC, 2006.

Recebido em outubro de 2009.

Aprovado para publicação em outubro de 2009

\section{Jaqueline Tittoni}

Professora do Pós-Graduação em Psicologia Social e Institucional da Universidade Federal do Rio Grande do Sul. Porto AlegreRS/Brasil

\section{Renata Ghisleni de Oliveira}

Aluna do Pós-Graduação em Psicologia Social e Institucional da Universidade Federal do Rio Grande do Sul. Porto Alegre-RS/ Brasil

\section{Paula Marques da Silva}

Aluna do Programa de Pós-Graduação em Psicologia Social e Institucional da Universidade Federal do Rio Grande do Sul. Porto Alegre-RS/Brasil

Grace Tanikado

Aluna do Programa de Pós-Graduação em Psicologia Social e Institucional da Universidade Federal do Rio Grande do Sul. Porto Alegre-RS/Brasil 